Supporting information for:

\title{
Enzyme Optimization and Process Development for a Scalable Synthesis of (R)-2-Methoxymandelic Acid
}

Mark E. Scott, Xiaotian Wang, Luke D. Humphreys* Michael J. Geier, Balamurali

Kannan, Johann Chan, Gareth Brown, Daniel F. A. R. Dourado, Darren Gray, Stefan

Mix, Aliaksei Pukin 


\section{$\underline{\text { Table of Contents }}$}

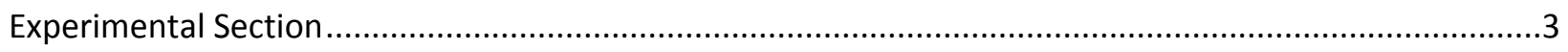

Expression of Burkholderia Cenocepacia J2315 Nitrilase (BCJ2315) for Initial Route Development:........3

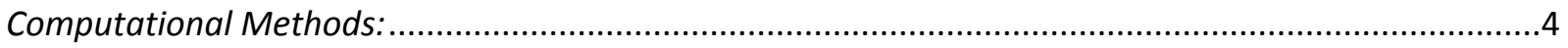

Generation of First Round of NIT BCJ2315 Mutants: ................................................................................

Evaluation of BCJ2315 Mutant Selectivity for Production of (R)-2-Methoxymandelic Acid (3): ..............7

Evaluation of BCJ2315 Mutant Activity for Production of (R)-2-Methoxy Mandelic Acid (3): .................8

Generation of Second Round of NIT BCJ2315 Mutants:.......................................................................8

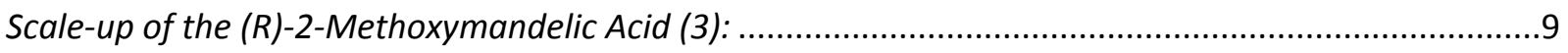

Preparation of 2-Methoxybenzaldehyde Bisulfite Adduct (4):..........................................................11

Bradford Assay for Residual Protein: .............................................................................................

HPLC Method for Enantiomeric Excess, Assay and IPC Analysis of (R)-2-Methoxymandelic Acid (3): ....13

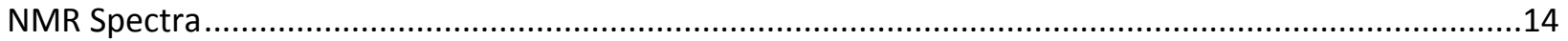

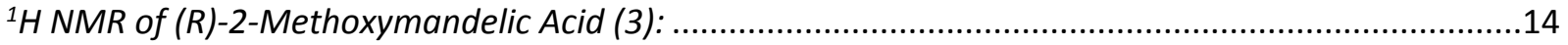

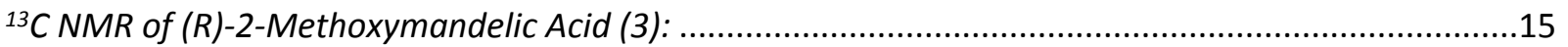

${ }^{1} \mathrm{H}$ NMR of 2-Methoxybenzaldehyde Bisulfite Adduct (4): ...............................................................16

${ }^{13}$ C NMR of 2-Methoxybenzaldehyde Bisulfite Adduct (4): ................................................................17

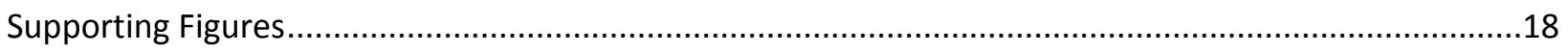

Figure S1: Reaction Profile at Variable Temperatures (Sustrate Concentration $100 \mathrm{~g}$ 1/L)....................18

Figure S2: BCJ2315 Model Docked to (S)-2-Chloromandelonitrile (left) and (R)-2-

Chloromandelonitrile (right). Distances are shown in Å. ................................................................19

Figure S3: SDS-PAGE of Select Best Performing Mutants. Lysates were Prepared by Freeze/thaw Lysis of the Material in 96-Well Screening Plates. Arrow Indicates the Corresponding Overexpressed NIT

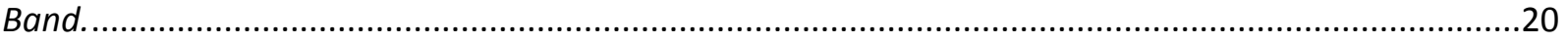

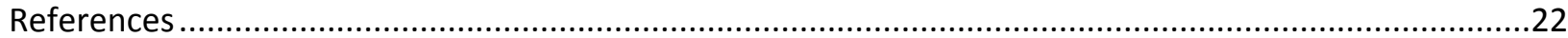




\section{Experimental Section}

Solvents and reagents were obtained from commercial sources and used without further purification. ${ }^{1} \mathrm{H}$ NMR was performed on a Bruker Avance III HD $400 \mathrm{MHz}$ spectrometer $\left({ }^{1} \mathrm{H}\right.$ NMR at $400 \mathrm{MHz},{ }^{13} \mathrm{C}$ NMR at $\left.101 \mathrm{MHz}\right)$ with solvent resonances as the internal standard $\left({ }^{1} \mathrm{H} \mathrm{NMR}\right.$ : DMSO-d6 at $2.50 \mathrm{ppm} ;{ }^{13} \mathrm{C}$ NMR: DMSO-d6 at $\left.39.52 \mathrm{ppm}\right) .{ }^{1} \mathrm{H}$ NMR data are reported as follows: chemical shift, integration, multiplicity $(s=$ singlet,$d=$ doublet,$t=$ triplet,$d d=$ doublet of doublets, $\mathrm{dt}=$ doublet of triplets), and coupling constants $(\mathrm{Hz}) . \mathrm{HPLC} / \mathrm{UPLC}$ was performed on an Agilent 1260 system equipped with a PDA detector. Bradford assay analysis was performed using an Agilent Cary 60 UV-Vis Spectrophotometer equipped with Cary Win UV software using BSA (lyophilized powder, Sigma) and Coomassie Plus Assay Reagent (ThermoFisher Scientific).

Expression of Burkholderia Cenocepacia J2315 Nitrilase (BCJ2315) for Initial Route Development:

BCJ2315 wild type enzyme (GenBank accession number: WP_012492804) was cloned into pET28a(+) at EcoR1 and Xhol and transformed into BL21 (DE3) cells (New England Biolabs). For primary cultures a single colony was transferred to $10 \mathrm{~mL}$ of terrific broth supplemented with $50 \mu \mathrm{g} / \mathrm{mL}$ kanamycin and incubated at $37{ }^{\circ} \mathrm{C}$ with shaking at $200 \mathrm{rpm}$ overnight. The primary culture was used to inoculate a $2.5 \mathrm{~L}$ flask containing $1 \mathrm{~L}$ of Luria-Bertani medium supplemented with $50 \mu \mathrm{g} / \mathrm{mL}$ kanamycin. Flasks were grown at $37{ }^{\circ} \mathrm{C}, 200 \mathrm{rpm}$ until $\mathrm{OD}_{600}$ reached $0.6-0.8$ then induced with IPTG at a final concentration of $0.4 \mathrm{mM}$ and incubated at $25^{\circ} \mathrm{C}, 200 \mathrm{rpm}$ for 16 hours. The flask contents were centrifuged at 5,500 rpm for $20 \mathrm{~min}$, the supernatant was removed and the cells were resuspended in $300 \% \mathrm{v} / \mathrm{w} 20 \mathrm{mM}$ potassium 
phosphate $(\mathrm{pH} 8.0)$. The resuspended cell pellet was centrifuged at 4,000 rpm for 15 minutes to remove residual culture media. The pellet was resuspended in $300 \% \mathrm{v} / \mathrm{w} 20 \mathrm{mM}$ potassium phosphate ( $\mathrm{pH} 8.0)$, lyophilized and stored at $4{ }^{\circ} \mathrm{C}$ until analysis.

\section{Computational Methods:}

A homology model of NIT BCJ2315 was built using templates crystals 3 wuy and $2 \mathrm{w} 1 \mathrm{v}$, which share $36 \%$ and $23 \%$ of sequence identity, respectively. This NIT BCJ 2315 homology model was then submitted to molecular dynamics (MD) simulations to better sample its $3 \mathrm{D}$ structure by placing it within an octahedral box of TIP3P waters. Counter ions were also added to reach neutrality. Two initial energy minimizations were performed, followed by an equilibration of 50 ps to slowly heat the system from 0 to $300^{\circ} \mathrm{K}$. The equilibration was performed in an NVT ensemble using Langevin dynamics with small restraints on the protein $(10 \mathrm{kcal} / \mathrm{mol})$.

Four random initial velocity 50 ns MD runs were performed using a time step of 0.002 ps. Periodic boundary conditions were used in an NPT ensemble (v-rescale thermostat ${ }^{1}$ and Parrinello-Rahman barostat ${ }^{2}-\tau_{T}=0.1 \mathrm{ps}, \mathrm{T}_{\text {ref }}=300 \mathrm{~K}, \mathrm{P}_{\text {ref }}=1$ bar). The Particle Mesh Ewald $(\mathrm{PME})^{3}$ method was applied with a cut-off of $1.0 \mathrm{~nm}$. A twin range cut-off with neighbor list cut-off 1.0 was used for the van der Waals interactions. All simulations and consequent analyses were carried out using the Gromacs 4.6 .5 software package conjugated with the PARM99 force field. ${ }^{4}$ A representative structure of the MD simulation, which corresponds to the lowest RMSD structure in relation to the average structure of the simulation, was used as an input for molecular docking. Molecular docking was performed using the AutoDock 4.2 suite 
of programs with the Lamarckian genetic algorithm (LGA) ${ }^{5}$ using a previously describe protocol. ${ }^{6}$

Generation of First Round of NIT BCJ2315 Mutants:

BCJ2315 mutants were cloned into pET28(a)+ and transformed into BL21 (DE3) cells. For primary cultures a single colony was transferred to $500 \mu \mathrm{L}$ of terrific broth supplemented with $50 \mu \mathrm{g} / \mathrm{mL}$ kanamycin and incubated at $37^{\circ} \mathrm{C}$ with shaking at $200 \mathrm{rpm}$ overnight. Production of the screening plates by inoculation of $10 \mu \mathrm{L}$ of primary culture into $1 \mathrm{~mL}$ of terrific broth supplemented with $50 \mu \mathrm{g} / \mathrm{mL}$ kanamycin. Plates were shaken at $37^{\circ} \mathrm{C}, 1,300 \mathrm{rpm}$ until $\mathrm{OD}_{600}$ reached $0.6-0.8$ then induced with IPTG at a final concentration of $0.4 \mathrm{mM}$ and incubated at $25^{\circ} \mathrm{C}, 200 \mathrm{rpm}$ for 16 hours. The plates were centrifuged at 2,000 rpm for 15 minutes, and the media was then removed, and the cell pellets resuspended in $100 \mu \mathrm{L}$ of $20 \mathrm{mM}$ potassium phosphate ( $\mathrm{pH}$ 8.0). The resuspended whole cells were lyophilized and stored at $4{ }^{\circ} \mathrm{C}$. The preferred mutant, M100, was grown successfully in a $5 \mathrm{~L}$ fed batch fermenter to produce sufficient material for downstream optimization efforts. In this case, the activity of this larger fermenter generated material was found to be comparable with shake flask expression. 
Table S1: First Round of NIT BCJ2315 Mutants

\begin{tabular}{|c|c|c|}
\hline \multicolumn{3}{|c|}{ First Round of NIT BCJ2315 Mutants } \\
\hline T134S & S62T & A323S \\
\hline T134V & S62P & A323N \\
\hline T134A & S62A & $A 3230$ \\
\hline $\mathrm{H} 135 \mathrm{~F}$ & A108S & A323T \\
\hline $\mathrm{H} 135 \mathrm{~A}$ & A108N & N81P \\
\hline W59F & A108G & N81D \\
\hline W59Y & A197N & $\mathrm{N} 81 \mathrm{H}$ \\
\hline W59l & A197T & D145N \\
\hline F141Y & A197P & M232V \\
\hline $\mathrm{F} 141 \mathrm{H}$ & L235R & C237V \\
\hline W165A & L235K & C237S \\
\hline W165V & $\mathrm{H} 242 \mathrm{~K}$ & E301D \\
\hline Y54F & V302T & A324S \\
\hline $\mathrm{Y} 54 \mathrm{H}$ & A64E & A324N \\
\hline T49N & A64S & A324Q \\
\hline T49C & G109S & A324T \\
\hline T49A & G109D & D145Q \\
\hline T49Q & Q231S & D145S \\
\hline T49V & Q231P & Y194F \\
\hline T49S & L236I & Y194H \\
\hline
\end{tabular}




\begin{tabular}{|c|c|c|}
\hline T49L & L236F & A175T \\
\hline I113N & L236M & A175V \\
\hline I113C & E269P & L201I \\
\hline I113L & Y199C & T310H \\
\hline I113M & Y199Q & T310L \\
\hline I113Q & Y199S & T310I \\
\hline S192A & Y199P & T310S \\
\hline S192G & Y199A & Y199G_I113M_T310H \\
\hline S192P & Y199G & N206Q \\
\hline S192C & S190A & L201V \\
\hline W188H & S190T & I113M_Y199G \\
\hline W188N & L201T & \\
\hline
\end{tabular}

Evaluation of BCJ2315 Mutant Selectivity for Production of (R)-2-Methoxymandelic Acid (3):

Freeze-dried whole cells $(5 \mathrm{mg})$ of BCJ2315 mutant enzymes were shaken for 1 hour in 96 well plate with $10 \mathrm{mg}$ of cyanohydrin 2 at a concentration of $10 \mathrm{mg} / \mathrm{mL}$ in $10: 1$ mixture of $0.1 \mathrm{M} \mathrm{Na}$ carbonate buffer $(\mathrm{pH} 9)$ and EtOAc at room temperature in a microplates shaker at $1500 \mathrm{rpm}$. Optical purity of $\mathbf{3}$ produced was determined by HPLC. 
Evaluation of BCJ2315 Mutant Activity for Production of (R)-2-Methoxy Mandelic Acid (3):

Freeze-dried whole cells $(0.5 \mathrm{mg})$ of BCJ2315 mutant enzymes were shaken for 2 hours in 96 well plate with $10 \mathrm{mg}$ of cyanohydrin 2 at a concentration of $10 \mathrm{mg} / \mathrm{mL}$ in $10: 1$ mixture of $0.1 \mathrm{M}$ sodium carbonate buffer $(\mathrm{pH} 9)$ and EtOAc at room temperature in a microplates shaker at 1500 rpm. Conversion of $\mathbf{2}$ to 3 was determined by HPLC.

Generation of Second Round of NIT BCI2315 Mutants:

A second round of mutants was prepared based on the results from $2 \mathrm{~g}$ scale screening reactions and further in silico analysis (Table S2). The mutants were generated by PCR SDM to introduce an amino acid substitution on the M25 plasmid sequence. Reactions were heated at $95{ }^{\circ} \mathrm{C}$ for 5 minutes prior to addition of $1 \mu \mathrm{L}$ Pfu phusion polymerase. PCR amplification was confirmed by agarose gel electrophoresis prior to proceeding to template removal. Following PCR $20 \mathrm{U}$ of Dpnl was added to the reaction and incubated at $37{ }^{\circ} \mathrm{C}$ for 2 hours to digest methylated template DNA. The PCR product was purified using a NEB Monarch PCR and DNA clean-up kit using manufacturer's protocols and eluted into nuclease free water. 
Table S2: Second Round of NIT Mutants via Site Directed Mutagenesis

\begin{tabular}{|c|c|c|c|c|}
\hline Mutant & $\begin{array}{c}\text { Previous } \\
\text { mutant } \\
\text { combination }\end{array}$ & $\begin{array}{c}\text { Sequence } \\
\text { mutations }\end{array}$ & $\begin{array}{c}\text { Mutant } \\
\text { template }\end{array}$ & SDM primer sequences $^{*}$ \\
\hline M99 & $\begin{array}{c}\text { M25 }+ \\
\text { M43 }\end{array}$ & $\begin{array}{c}\text { S192G, } \\
\text { Y199Q }\end{array}$ & M25 & MCGGGTGCGGCG F : \\
\hline M100 & M25 + & $\begin{array}{c}\text { S192G, } \\
\text { M232V }\end{array}$ & M25 & M43 R: \\
\hline
\end{tabular}

* Lowercase nucleotides within the primer sequence designate the site of amino acid mutation.

The mutant plasmid $(1 \mu \mathrm{L})$ was transformed into TOP10 (Thermo Fisher Scientific) chemically competent $E$. coli using standard protocols and transformation reactions and were plated on nutrient agar supplemented with $50 \mu \mathrm{g} / \mathrm{mL}$ kanamycin. Three colonies per transformation were grown in $10 \mathrm{~mL}$ of TB media supplemented with $50 \mu \mathrm{g} / \mathrm{mL}$ kanamycin overnight at $37^{\circ} \mathrm{C}$ and $200 \mathrm{rpm}$. The plasmids were purified using NEB Monarch plasmid miniprep kit (New England Biolabs) according to manufacturer's instructions and stored at $-80^{\circ} \mathrm{C}$. A portion of the purified plasmid was sequenced using T7 promoter and terminator primers. Plasmids confirmed to have successful mutant generation by SDM were transformed into BL21 (DE3) and grown and expressed at $1 \mathrm{~L}$ scale.

Scale-up of the (R)-2-Methoxymandelic Acid (3):

To a solution of 2-methoxybenzaldehyde $(40.00 \mathrm{~g}, 293.8 \mathrm{mmol}, 1.00$ equiv) in ethyl acetate (40.03 g) was added solid $\mathrm{NaHSO}_{3}$ (30.58 g, $293.9 \mathrm{mmol}, 1.00$ equiv) and water (300.04 g). After 
the addition was complete, the reaction mixture was agitated for an additional ca. 60 minutes, resulting in a colorless hazy solution. To this reaction mixture was then slowly added a solution of $\mathrm{NaCN}$ (14.69 g, $299.7 \mathrm{mmol}, 1.02$ equiv) in water (60.03 g) while maintaining the pot temperature below $25^{\circ} \mathrm{C}$. After the addition was complete, the reaction mixture was agitated for an additional ca. 60 minutes. To this reaction mixture was then added M100 dried whole cell enzyme ( $2.04 \mathrm{~g}, 5 \% \mathrm{w} / \mathrm{w}$ relative to the aldehyde). After the addition was complete, the reaction mixture was agitated for an additional 24 to 48 hours until the reaction was deemed complete by HPLC. The reaction mixture was then filtered through a layer of Celite and the reactor and Celite were rinsed forward with water $(40.02 \mathrm{~g})$. The combined filtrate (caution: trace $\mathrm{NaCN}$ may still be present in the filtrate) were washed with ethyl acetate (40.03 g). The organic layer was discarded and the aqueous layer was acidified to $\mathrm{pH} 1$ with conc. $\mathrm{HCl}$ resulting in formation of an emulsion. $\mathrm{MgSO}_{4}(80.05 \mathrm{~g})$ was then added to the aqueous layer and the resulting solution was stirred for ca. 15 minutes to break the emulsion. Ethyl acetate (100.04 g) was then added and the resulting rag layer at the interface was removed via a polish filtration. The organic layer was removed and the aqueous layer was extracted with ethyl acetate $(2 \mathrm{x}$ $100.05 \mathrm{~g})$. The combined organic layers were concentrated under vacuum to approximately $60 \mathrm{~mL}$ (ca. 1.5 volumes) using a reactor jacket temperature of approximately $55^{\circ} \mathrm{C}$. Diisopropyl ether $(60.03 \mathrm{~g})$ was then added in one portion to the resulting pale yellow hazy solution and agitated at about $65^{\circ} \mathrm{C}$ for approximately 1 hour. The reaction mixture was then cooled over 2 hours to approximately $50^{\circ} \mathrm{C}$, then seed $(0.1216 \mathrm{~g})$ was charged resulting in slurry formation. Once a slurry was confirmed, heptanes (40.05 g) was charged over not less than 2 hours. After addition, the slurry was then cooled over about 7 hours to approximately $-20^{\circ} \mathrm{C}$ and agitated at 
$-20{ }^{\circ} \mathrm{C}$ for not less than 3 hours. The final product was filtered and washed with precooled diisopropyl ether $(40.05 \mathrm{~g})$ at about $-10^{\circ} \mathrm{C}$. The final solids were dried at $45^{\circ} \mathrm{C}$ in a vacuum oven with nitrogen sweep for not less than 4 hours to provide $37.27 \mathrm{~g}$ of the title compound (70\% yield, $99.10 \%$ assay purity, 96.89 ee\% determined by UPLC at $283 \mathrm{~nm}$ ) as a white solid. Average yields ranged from $60-75 \%$ with a purity range of $95-103$ assay\% by qNMR and $96-100 \%$ ee by UPLC at $283 \mathrm{~nm}$.

${ }^{1} \mathrm{H}$ NMR (DMSO-d $\left.6,400 \mathrm{MHz}\right) \delta: 12.34(1 \mathrm{H}$, broad s), $7.35(1 \mathrm{H}, \mathrm{dd}, J=1.8,7.4 \mathrm{~Hz}), 7.27(1 \mathrm{H}, \mathrm{dt}$, $J=2.0,7.8 \mathrm{~Hz}), 6.97(1 \mathrm{H}, \mathrm{d}, J=8.4 \mathrm{~Hz}), 6.94(1 \mathrm{H}, \mathrm{dt}, J=0.8,3.6 \mathrm{~Hz}), 5.30(1 \mathrm{H}, \mathrm{s}), 3.77(3 \mathrm{H}, \mathrm{s})$;

${ }^{13} \mathrm{C}$ NMR (DMSO- $\left.d_{6}, 100 \mathrm{MHz}\right) \delta: 174.4,156.6,129.1,128.8,128.0,120.4,111.2,67.0,55.6$.

Preparation of 2-Methoxybenzaldehyde Bisulfite Adduct (4):

The bisulfite adduct 4 was prepared according to a general procedure previously reported by Kissane et al. ${ }^{7}$ To a solution of 2-methoxybenzaldehyde (10.02 g, $73.60 \mathrm{mmol}, 1.00$ equiv) in ethanol (103.06 g) was added solution of $\mathrm{NaHSO}_{3}(7.65 \mathrm{~g}, 73.50 \mathrm{mmol}, 1.00$ equiv) in water (18.03 g). After the addition was complete, the reaction mixture was agitated for an additional ca. 2 hours, resulting in a white thick slurry. The final product was filtered and washed sequentially with premixed ethanol (10.04 g) and water (10.03 g). The final solids were dried at $40{ }^{\circ} \mathrm{C}$ in a vacuum oven with nitrogen sweep for not less than 10 hours to provide $15.69 \mathrm{~g}$ of the title compound ( $89 \%$ yield) as a white solid. 
${ }^{1} \mathrm{H}$ NMR (DMSO-d $\left.{ }_{6}, 400 \mathrm{MHz}\right) \delta: 7.59(1 \mathrm{H}, \mathrm{dd}, J=1.7,7.6 \mathrm{~Hz}), 7.19(1 \mathrm{H}, \mathrm{dd}, J=1.7,7.3 \mathrm{~Hz})$, 6.85-6.91 (2H, m), $5.74(1 \mathrm{H}, \mathrm{d}, J=6.0 \mathrm{~Hz}), 5.45(1 \mathrm{H}, \mathrm{d}, J=6.0 \mathrm{~Hz}), 3.74(3 \mathrm{H}, \mathrm{s}) ;{ }^{13} \mathrm{C}$ NMR (DMSO$\left.d_{6}, 100 \mathrm{MHz}\right) \delta: 156.8,129.0,128.4,128.1,119.6,110.6,77.4,55.7$.

Bradford Assay for Residual Protein:

A standard calibration curve was generated using BSA protein using a 2 to $100 \mathrm{ppm}$ aqueous stocks solutions prepared by dissolution of BSA in Milli-Q water. Samples were prepared by dissolving approximately $0.1 \mathrm{~g}$ of sample and dissolving it in $1.0 \mathrm{~mL}$ Milli-Q water. Both standard and sample measurements were obtained by pipetting $1.0 \mathrm{~mL}$ of the standard or sample solution into a cuvette containing $1.5 \mathrm{~mL}$ of the Coomassie Plus Bradford assay reagent. The solution was gently mixed and allowed to stand for 5 minutes at ambient temperature. Net UV absorbance for both the standard and sample solutions was then measured according to the following calculation:

Net UV absorbance $=$ Absorbance at $595 \mathrm{~nm}-$ Absorbance at $465 \mathrm{~nm}$

A BSA standard calibration curve was then obtained by fitting the absorbance for the various standards relative to the $\mu \mathrm{g}$ of BSA protein present in $1.0 \mathrm{~mL}$ of sample solution. Protein content (in $\mu \mathrm{g} / \mathrm{g}$ ) of the samples can then be calculated using their net UV absorbance and the BSA calibration curve to obtain the protein content in $\mu \mathrm{g} / \mathrm{sample}$ weight in grams. 
HPLC Method for Enantiomeric Excess, Assay and IPC Analysis of (R)-2-Methoxymandelic Acid

(3):

\begin{tabular}{|l|l|}
\hline Column & CHIRALPAK IC-3, $4.6 \times 250 \mathrm{~mm}, 5 \mu \mathrm{m}$ \\
\hline Flow rate & $1 \mathrm{~mL} / \mathrm{min}$ \\
\hline Eluent & $\begin{array}{l}\text { Hexane with } 0.1 \% \text { TFA: } 85 \% ; \\
\text { Ethyl acetate with 0.1\% TFA: } 15 \%\end{array}$ \\
\hline Injection volume & $10.0 \mu \mathrm{L}$ \\
\hline Temperature & $20^{\circ} \mathrm{C}$ \\
\hline Detector & $\mathrm{PDA}$ \\
Wavelength & $283 \mathrm{~nm}$ \\
\hline Run Time & 30 minutes \\
\hline
\end{tabular}




\section{NMR Spectra}

${ }^{1}$ H NMR of (R)-2-Methoxymandelic Acid (3):

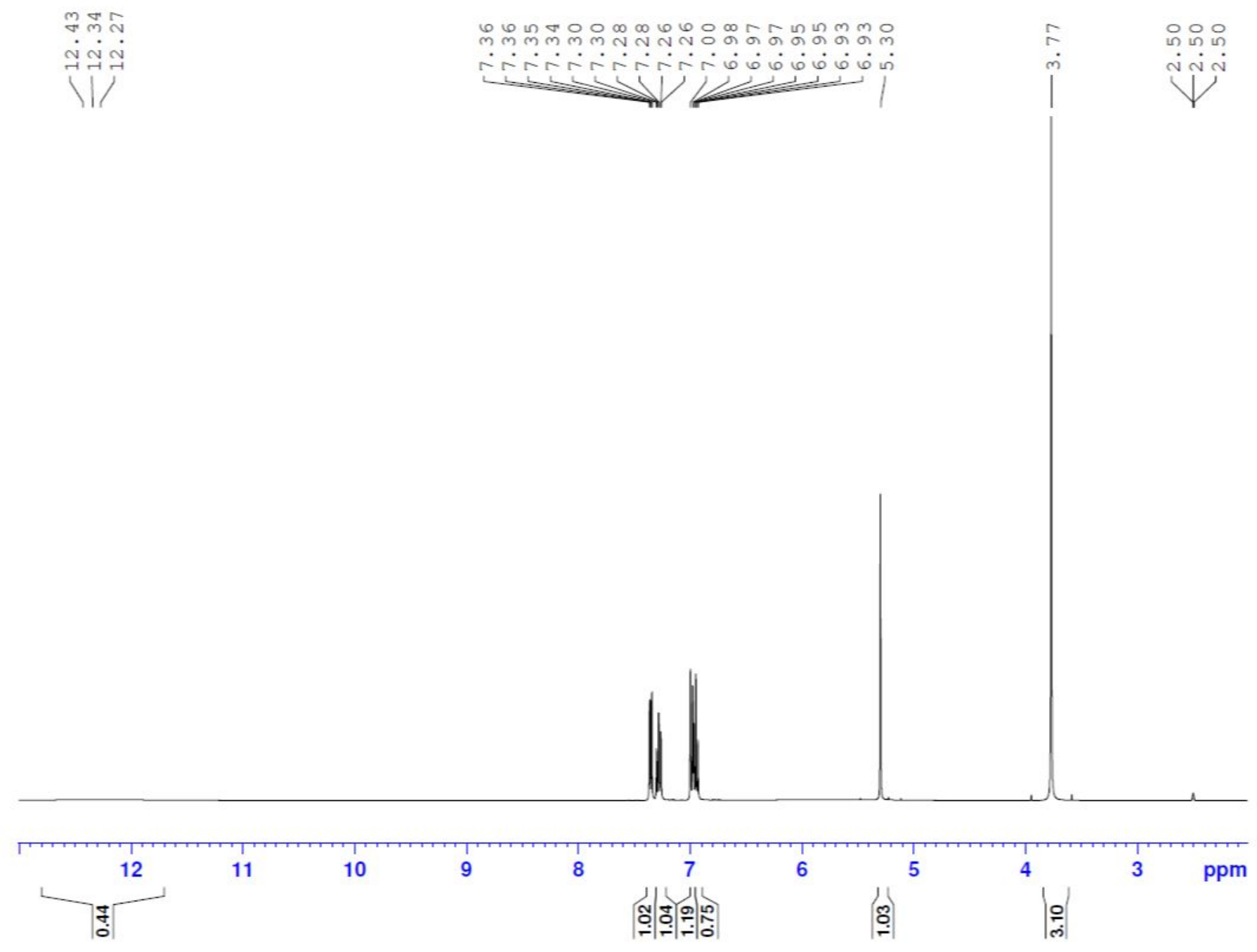


${ }^{13}$ C NMR of (R)-2-Methoxymandelic Acid (3):
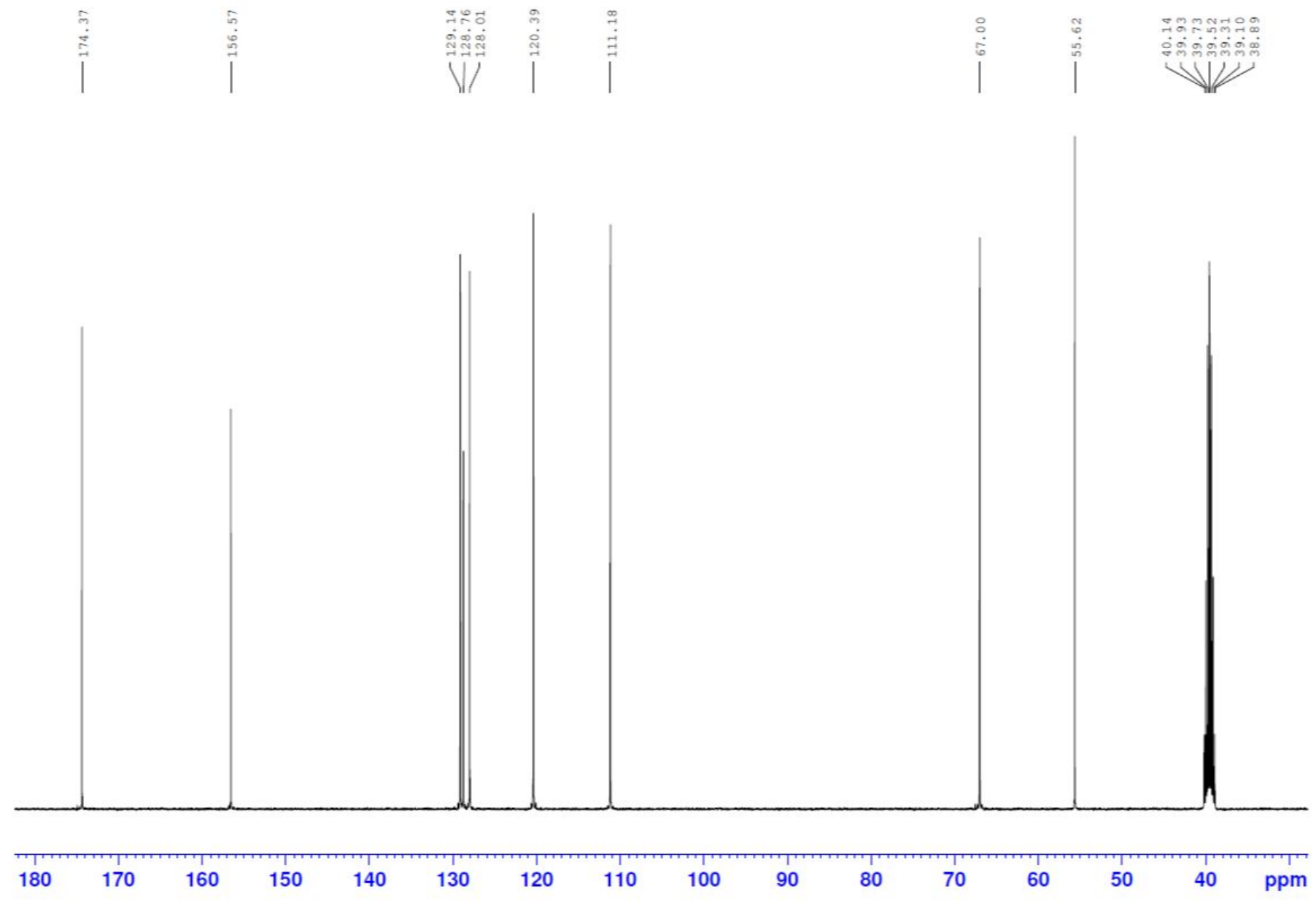
${ }^{1}$ H NMR of 2-Methoxybenzaldehyde Bisulfite Adduct (4):

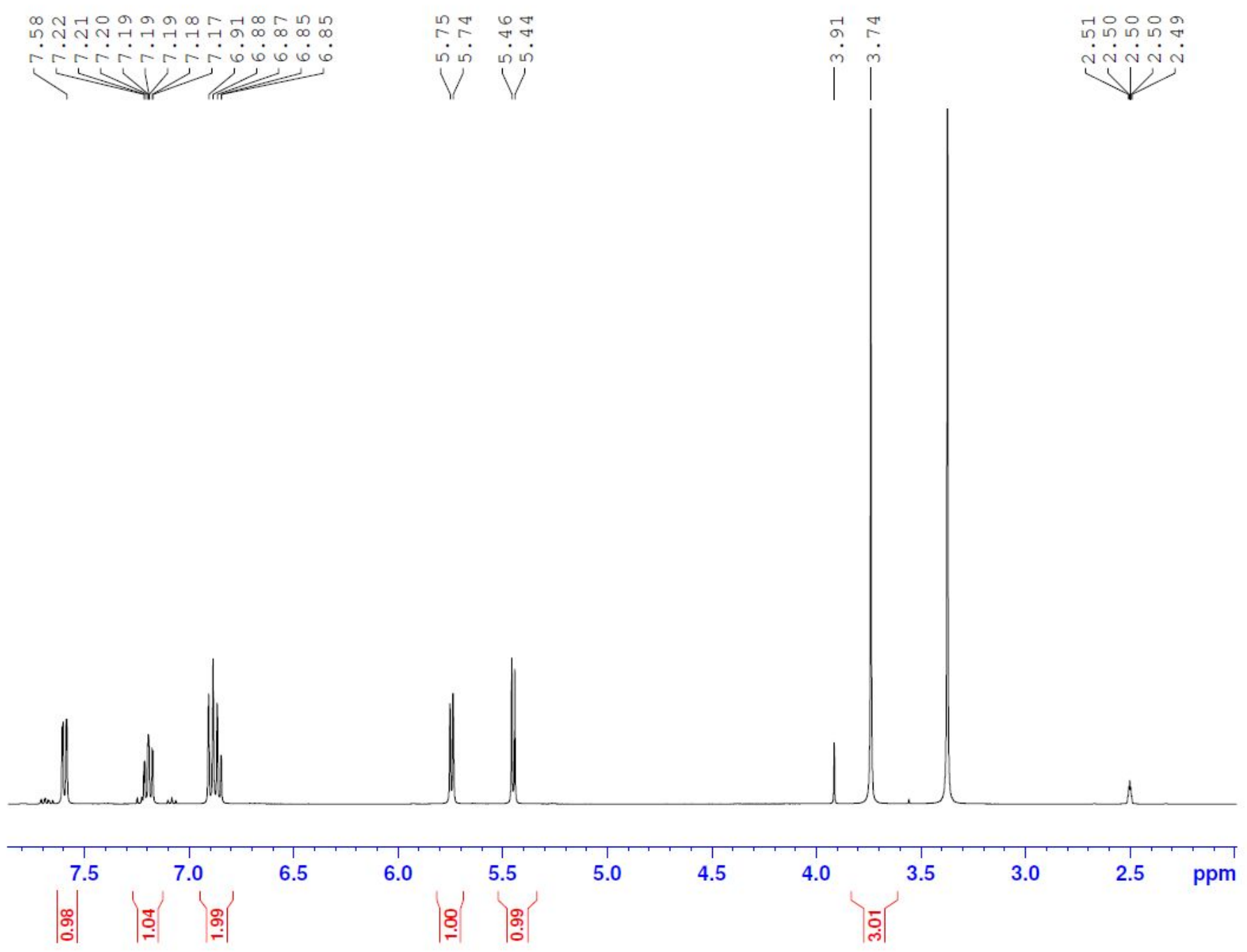


${ }^{13}$ C NMR of 2-Methoxybenzaldehyde Bisulfite Adduct (4):
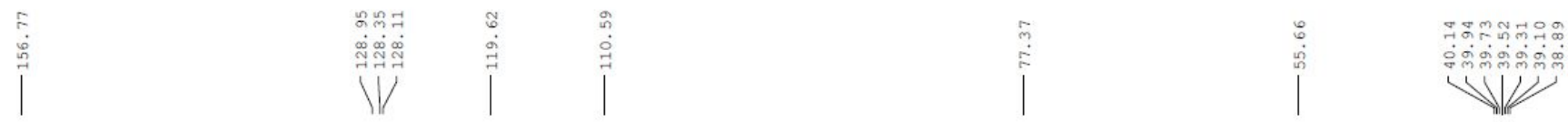

政

WW
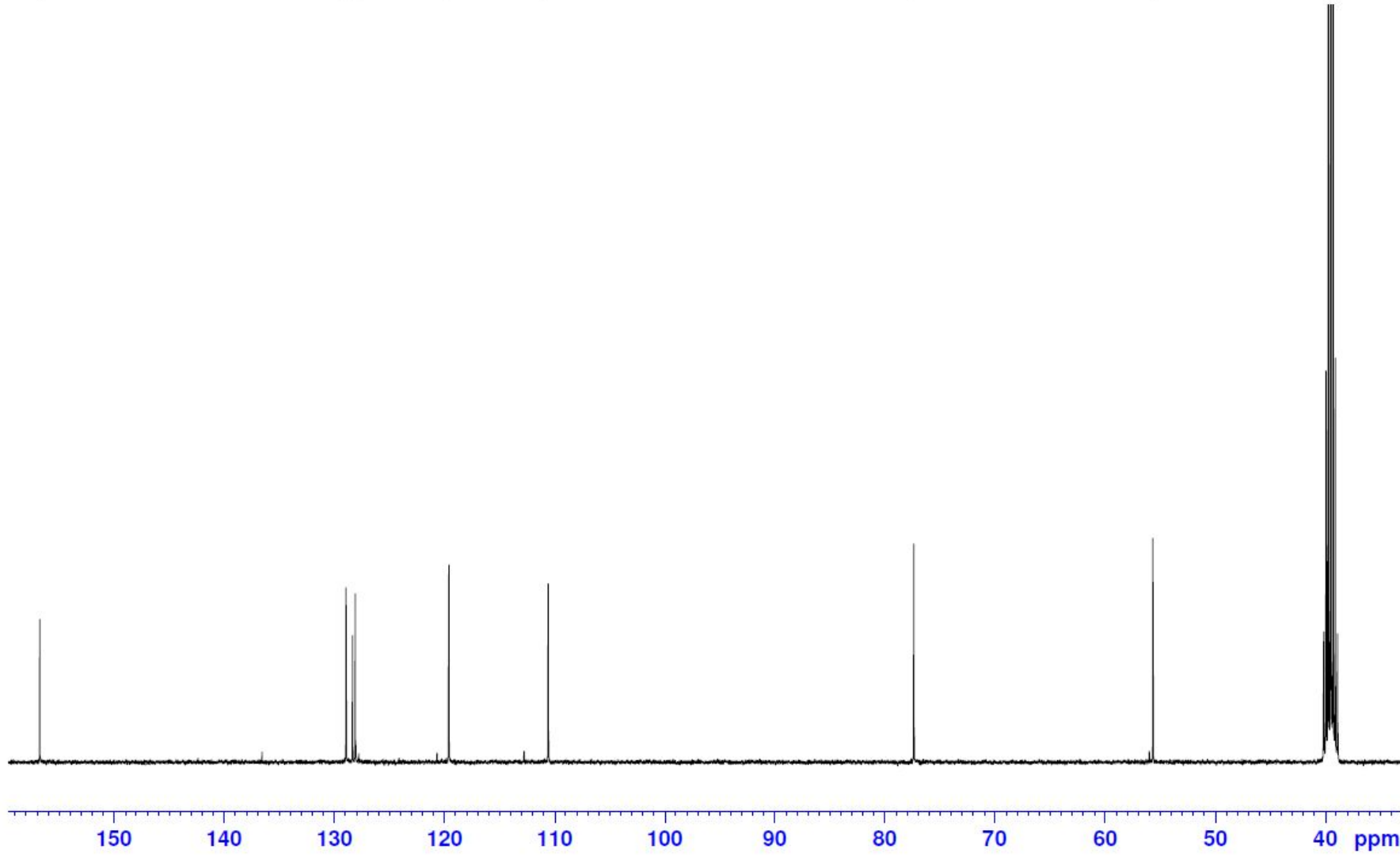


\section{Supporting Figures}

Figure S1: Reaction Profile at Variable Temperatures (Substrate Concentration $100 \mathrm{~g}$ 1/L)

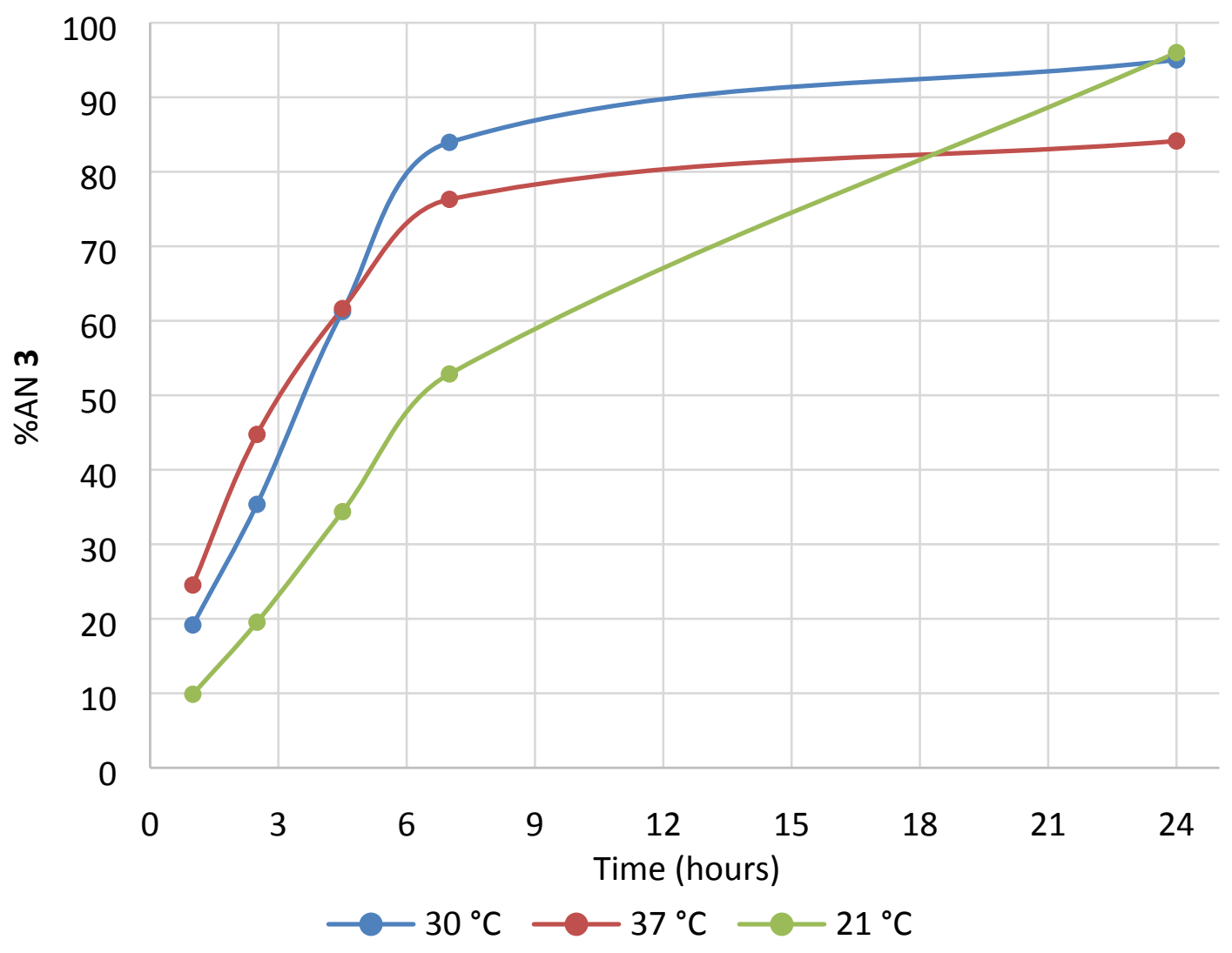


Figure S2: BCJ2315 Model Docked to (S)-2-Chloromandelonitrile (left) and

(R)-2-Chloromandelonitrile (right). Distances are shown in $\AA$.

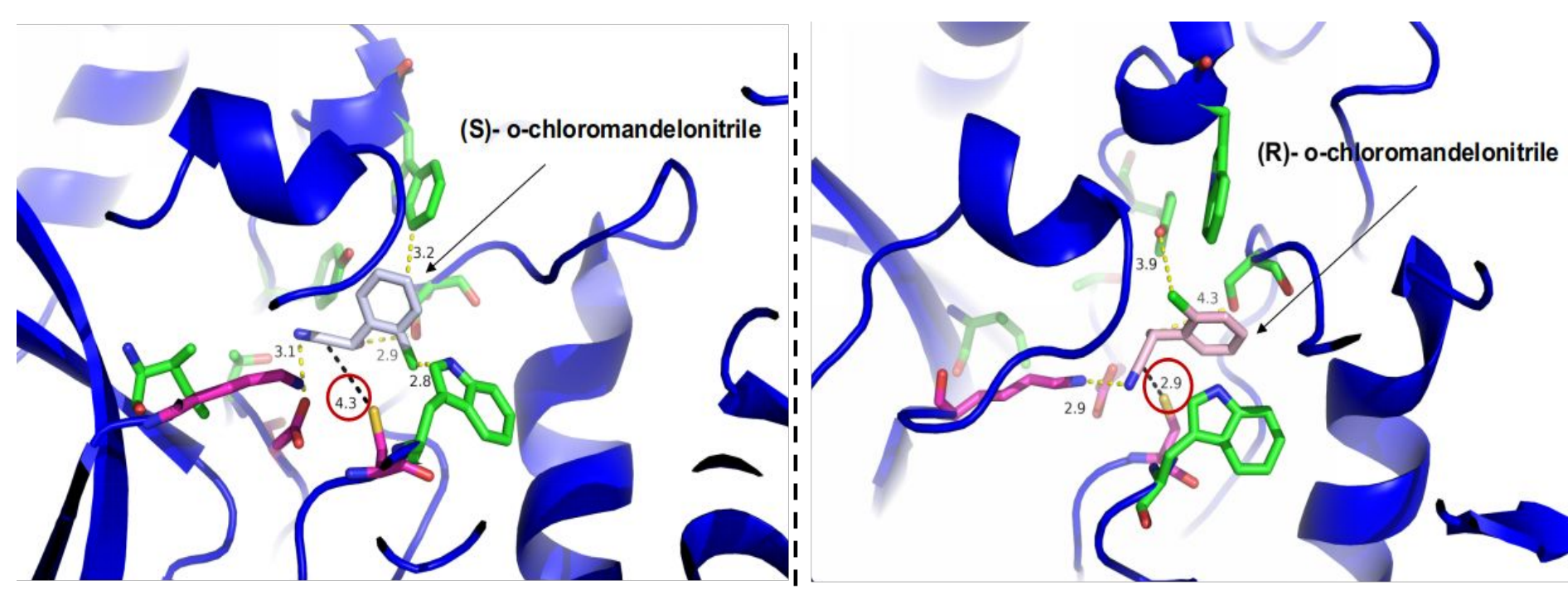


Figure S3: SDS-PAGE of Select Best Performing Mutants. Lysates were Prepared by Freeze/thaw Lysis of the Material in 96-Well Screening Plates. Arrow Indicates the Corresponding Overexpressed NIT Band.

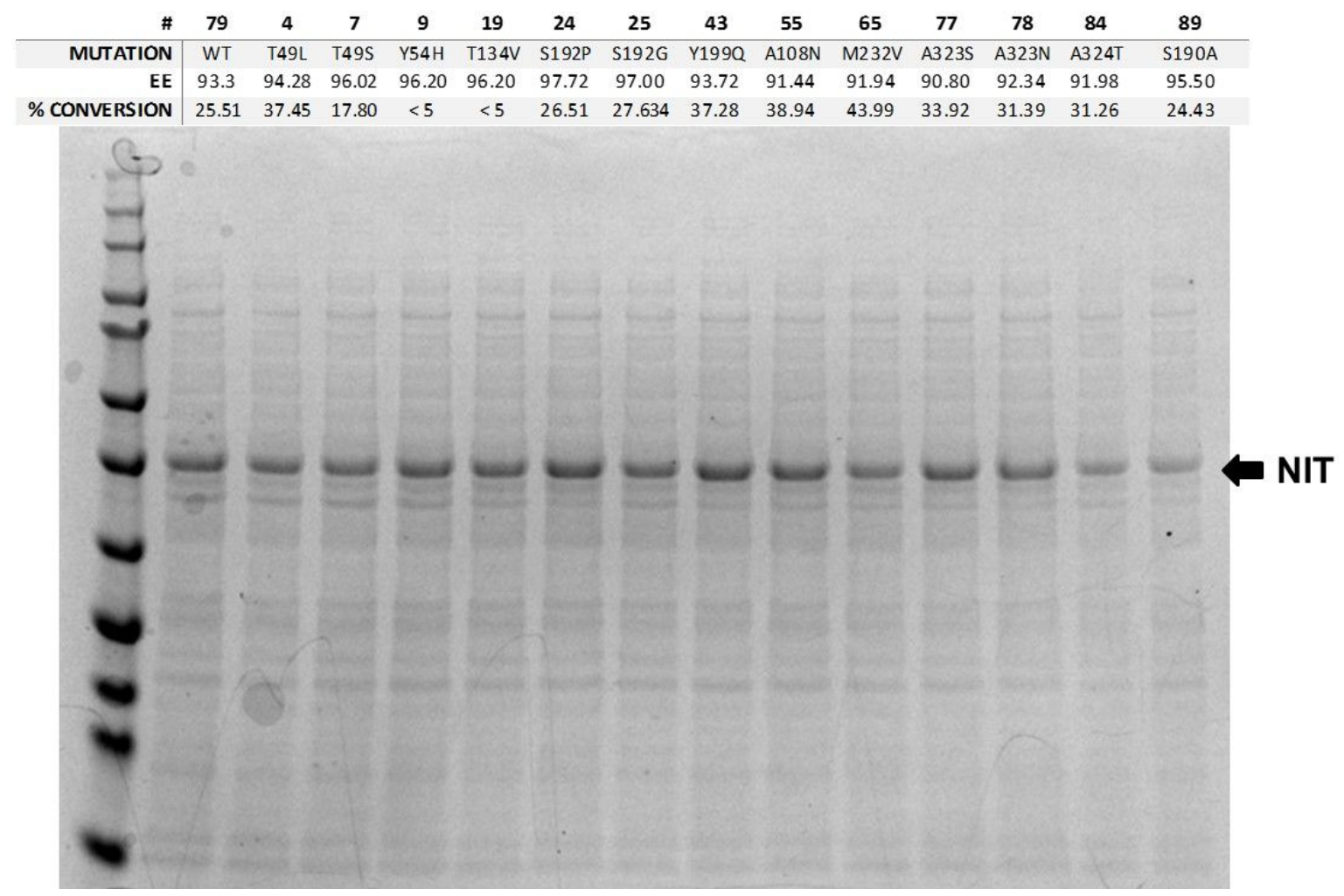


Figure S4: B-Factor Values of WT NIT BCJ2315: MD replica 1 (red dash); MD replica 2 (blue X);

MD replica 3 (black dot); MD replica 4 (green triangle).

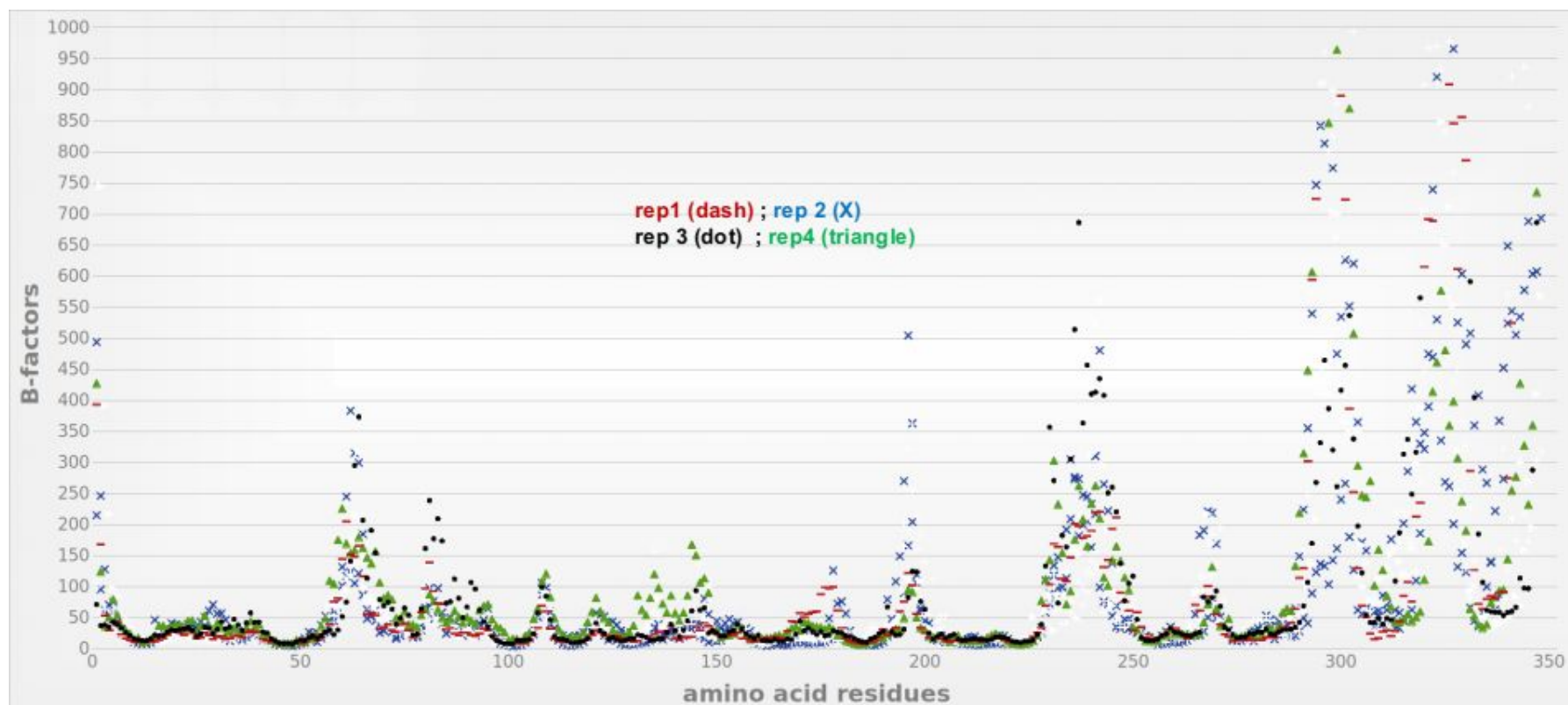




\section{References}

1. Bussi, G.; Donadio, D.; Parrinello, M. Canonical Sampling Through Velocity Rescaling. J. Chem. Phys. 2007, 126, 014101/1-014101/7.

2. Parrinello, M.; Rahman, A. Polymorphic Transitions in Single Crystals: A New Molecular Dynamics Method. J. Appl. Phys. 1981, 52, 7182-7190.

3. Essmann, U.; Perera, L.; Berkowitz, M. L.; Darden, T.; Lee, H.; Pedersen, L. G. A Smooth Particle Mesh Ewald Method. J. Chem. Phys. 1995, 103, 8577-8593.

4. Pronk, S.; Páll, S.; Schulz, R.; Larsson, P.; Bjelkmar, P.; Apostolov, R.; Shirts, M. R.; Smith, J. C.; Kasson, P. M.; van der Spoel, D.; Hess, B.; Lindahl, E. GROMACS 4.5: A High-throughput and Highly Parallel Open Source Molecular Simulation Toolkit. Bioinformatics 2013, 29, 845-854.

5. Morris, G. M.; Huey, R.; Lindstrom, W.; Sanner, M. F.; Belew, R. K.; Goodsell, D. S.; Olson, A. J. AutoDock4 and AutoDockTools4: Automated Docking with Selective Receptor Flexibility. J. Comput. Chem. 2009, 30, 2785-2791.

6. (a) Carvalho, A. T. P.; Dourado, D.; Skvortsov, T.; de Abreu, M.; Ferguson, L. J.; Quinn, D. J.; Moody, T. S.; Huang, M. Spatial Requirement for PAMO for Transformation of Non-native Linear Substrates. Phys. Chem. Chem. Phys. 2018, 20, 2558-2570. (b) Dourado, D. F. A. R.; Pohle, S.; Carvalho, A. T. P.; Dheeman, D. S.; Caswell, J. M.; Skvortsov, T.; Miskelly, I.; Brown, R. T.; Quinn, D. J.; Allen, C. C. R.; Kulakov, L.; Huang, M.; Moody, T. S. Rational Design of a (S)Selective-Transaminase for Asymmetric Synthesis of (1S)-1-(1,1'-Biphenyl-2-yl)ethanamine. ACS Catal. 2016, 6, 7749-7759.

7. Kissane, M. G.; Frank, S. A.; Rener, G. A.; Ley, C. P.; Alt, C. A.; Stroud, P. A.; Vaid, R. K.; Boini, S. K.; McKee, L. A.; Vicenzi, J. T.; Stephenson, G. A. Counterion Effects in the Preparation of Aldehyde-bisulfite Adducts. Tetrahedron Lett. 2013, 54, 6587-6591. 